Joyce V. Zwartkruis, Holger Berg, Andries F. Hof, Marcel T. J. Kok

\title{
Agricultural nature conversation in the Netherlands: Three lenses on transition pathways
}

Originally published in:

Technological Forecasting \& Social

Change, 151 (2020), 119235

DOI: 10.1016/j.techfore.2018.03.0o6 
Joyce V. Zwartkruis a

Holger Berg $b$,*

Andries F. Hof a,c

Marcel T.J. Kok a

\section{Agricultural nature conversation in the Netherlands: Three lenses on transition pathways}

a PBL Netherlands Environmental Assessment Agency, Netherlands

b Wuppertal Institut für Klima, Umwelt, Energie gGmbH, Wuppertal, Germany

c Copernicus Institute of Sustainability Development, Utrecht University, Netherlands

* Corresponding author:

Holger Berg

Wuppertal Institut für Klima, Umwelt, Energie gGmbH

Döppersberg 19

42103 Wuppertal

Germany

E-mail: holger.berg@wupperinst.org

Phone: +49 202 2492-179

Fax: +49 202 2492-108

This is the author's version of a work that was accepted for publication. Changes resulting from the publishing process, such as editing, corrections and structural formatting, may not be reflected in this document. Changes may have been made to this work since it was submitted for publication. A definitive version was subsequently published in the Journal cited above. 


\title{
Agricultural nature conservation in the Netherlands: three lenses on transition pathways
}

\author{
Joyce V. Zwartkruis' ${ }^{1}$, Holger Berg ${ }^{2}$, Andries F. Hof ${ }^{1,3}$ and Marcel T.J. Kok ${ }^{1}$ \\ 1 PBL Netherlands Environmental Assessment Agency \\ ${ }^{2}$ Wuppertal Institut für Klima, Umwelt, Energie \\ ${ }^{3}$ Copernicus Institute of Sustainable Development, Utrecht University \\ *corresponding author
}

Acknowledgement: The paper is an outcome of the PATHWAYS project which received funding from the European Union's Seventh Framework Programme for Research, Technological Development and Demonstration under Grant Agreement No. 603942.

\begin{abstract}
In this paper three approaches on transitions pathways are bridged to study the role of agricultural nature conservation in a sustainability transition of the Dutch land use domain. Sustainability transitions in the way society uses land involve a vast number of actors and institutions on very different levels, from individual farmers and consumers over companies or social groups to national or supranational systems. The analysis of these complex transitions can profit from different research lenses. The three perspectives used are the Multilevel Perspective (MLP), Initiative Based Learning (IBL) and Integrated Assessment Modelling (IAM). The analysis provided insights in how the combination of different research approaches may improve the understanding of certain empirical observations related to the studied transitions. IAM provides insight in the measures needed to achieve global sustainability goals on biodiversity and climate while ensuring food supply, and MLP and IBL provide insights in how far these measures are realistic based on current developments in the agricultural and nature regime and on practices at the local level. This is important because a lot of measures and modifications ask for changes at the local level, and studying real life interactions and social relations provides insight into these mechanisms. A combined perspective caters for a deeper understanding of the underlying processes, reasons and motives as well as points towards potential future development and opportunities for intervention.
\end{abstract}

\section{Introduction}

In order to achieve internationally agreed sustainability goals related to biodiversity and climate change, transitions away from business as usual are required. The way in which land is used plays an important role in such sustainability transitions, as many environmental, social, and economic sustainability goals relate to land use and the affiliated externalities [1-3]. More concretely, habitat loss due to land use change is often considered to be a primary driver for biodiversity decline [4]. Furthermore, land use is responsible for a large share of greenhouse gas emissions, with $\mathrm{CO}_{2}$ emissions from forestry and other land use contributing about $10 \%$ to global emissions [5]. Changes in land use are therefore crucial for achieving biodiversity and climate targets, such as agreed under the Convention on Biological Diversity (CBD) and the Paris Agreement [6], while at the same time the important role of land for food production has to be acknowledged. 
Sustainability transitions in the way society uses land involve a vast number of actors and institutions on very different levels, from individuals and farmers over companies or social groups to national or supranational systems. Hence, transitions are complex in many ways, and can be characterized by a large number of degrees of freedom concerning their development, path dependency, historicity, and other influences [7-9]. Improved knowledge is needed for the design of new agricultural systems that combine ecological resilience with efficient technologies. This is important because most of the currently known ecological solutions are labour-intensive, which the farming industry increasingly wants to avoid. Therefore, it is more than unlikely that one scientific school, method or discipline can capture and understand the whole antecedents, prerequisites, processes and outcomes that relate to sustainability transitions. However, since many of the required changes are urgently needed and already taking place, it is necessary to understand, monitor and potentially influence them. Science can contribute to this by providing insight into sustainability transitions and deriving implications on how these can be governed [cf. 10,11].

Given these complexities, methods and procedures to interpret sustainability transitions from different scientific angles need to be applied, the findings of which should be combined or compared in what could be understood as an effort of inter- and transdisciplinary triangulation [12]. Combining the findings made by different approaches may lead to a more encompassing and robust understanding of the processes, outcomes, and impacts of sustainability transitions. They may thus also produce more appropriate and legitimate implications for practice and policy [13].

In this paper we experiment with such a joint approach by using three methodological lenses on transitions. We study the development around agricultural nature conservation in the Netherlands, with the aim to gain insights on whether and how agricultural nature conservation could help to achieve internationally agreed sustainability goals related to climate change and biodiversity. The three methodological lenses applied are socio-technical analysis in a multi-level perspective (MLP), integrated assessment modelling (IAM) and initiative-based learning (IBL). As discussed by Turnheim et al [14], each of these lenses has its own strengths and weaknesses, and combining these provides a basis for a more robust and complete analysis of sustainable transitions pathways. In this first, exploratory attempt to combine the insights from these different lenses, we compare, contrast and combine results derived from the three research approaches. From this effort we deduct areas of potential interactions in further research on sustainability transitions.

Different definitions of agricultural nature conservation exist. In the broadest sense it refers to the measures farmers are taking on and surrounding their farm that help to protect nature and the landscape, with agricultural production remaining the most important function. Different forms of agricultural nature conservation measures can be distinguished, including species management, border management, parcel management, and management and development of landscape elements [15]. Examples of measures include protecting meadow birds and maintaining a diversity of plant species in and around the fields. As such measures will generally lead to decreases in contemporary agricultural production and hence income, farmers are usually compensated for this loss. The Netherlands was chosen for our study as the Netherlands is a small country with high population density, so that every space has one or more particular functions. 
The paper proceeds as follows. Section 2 characterises the three approaches and lays out the procedures for the joint approach taken here. It points out what the approaches can contribute and what their specific advantages and limitations are in understanding the aforementioned transition. Section 3 outlines the present transition process in the Dutch land use domain and offers relevant insights gained from applying the three approaches individually. In Section 4 the findings are combined to point out how a common effort elucidates this transition more aptly than single-approach undertakings. Section 5 concludes.

\section{Theory}

Below we describe the three approaches central to this paper.

\subsection{Socio-technical analysis in a multi-level perspective}

"Socio-technical analysis, which is an approach in the domain of innovation studies, investigates interactions between technical and social dimensions (including economic, cultural and political dimensions). It is sociological in the sense of focusing on the various groups of social actors that interact in the reproduction and change of sociotechnical systems" [16, p. 4]. The approach relies on the Multilevel Perspective (MLP) in which the interdependent relations, dynamics and impact of three distinct levels are analysed: niche innovation, socio-technical regimes, and socio-technical landscape [17, 18]. Regimes influence all related processes in their area of dominance, stabilizing the system trajectory through mechanisms such as sunken investments, dominant customs, networks etc. Niches are conceptualized as the micro-level in which radical innovation originates; they are formed by local projects that eventually join to constitute niches as higher order analytical entities. The socio-technical landscape resembles the exogenous environment of a regime and is not susceptible to the influence of niche and regime actors [18 cf. also for a more distinct conceptualization of all three levels]. From a sociotechnical transition perspective transitions can be pictured as in Figure 1. 
Increasing structuration

of activities in local practices

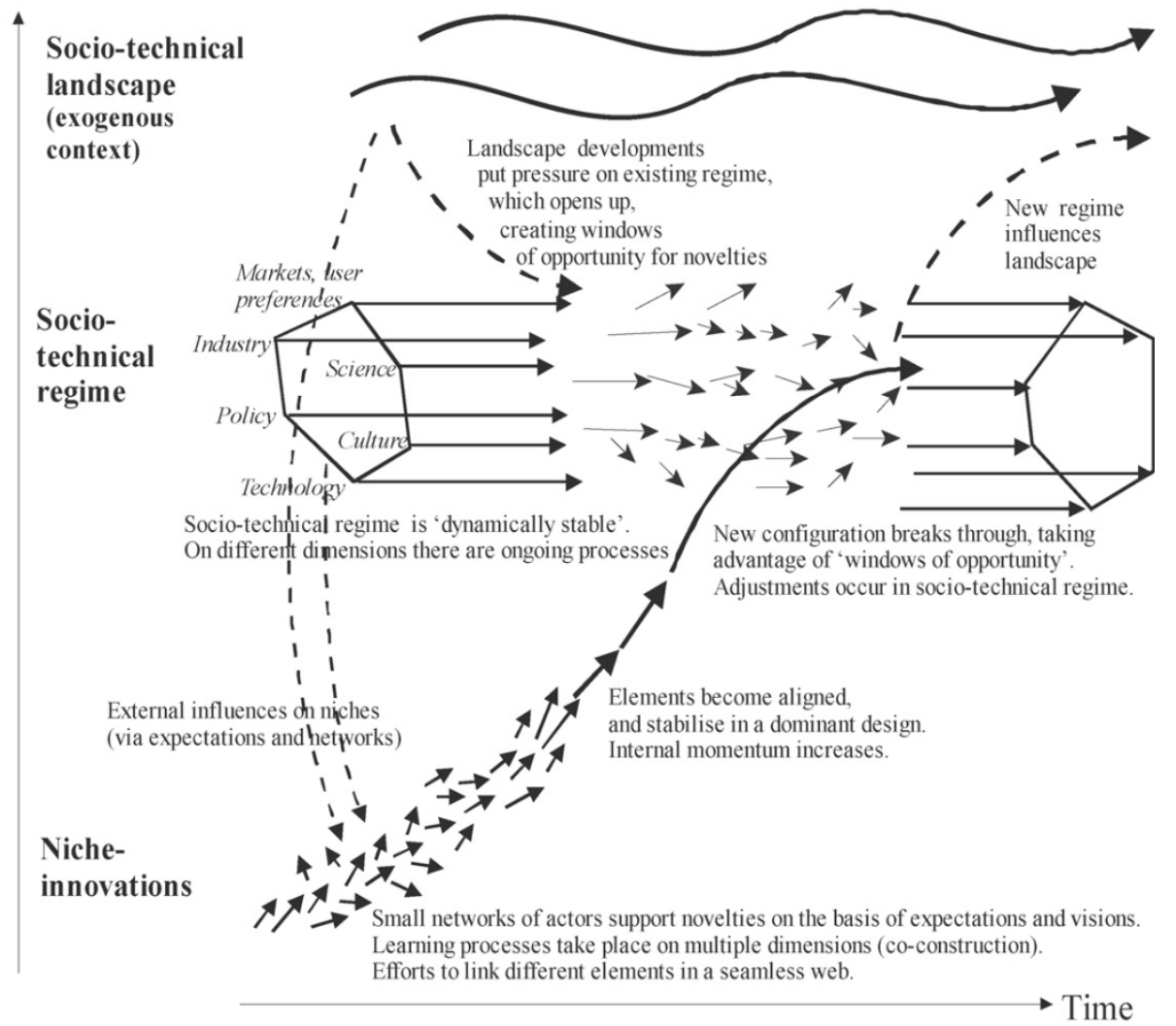

Figure 1: Multi-level perspective on transitions [18 p. 401].

An important strength of this approach lies in its deep attention to the specific contexts and nuances of (historic) real-world processes and in the consideration of a broad range of interdependent influences such as agency, institutional constellations and development, as well as mechanisms such as path dependency and causation [14]. As most evolutionary oriented research approaches, this approach is limited with regard to its predictive capabilities and is more stylized and less tangible than e.g. initiative-based learning. Due to a mainly descriptive and qualitative character, generalisation is limited. In land use, changes are bounded by spatial and ecological characteristics as well, and not only by technological feasibility.

When studying innovations in land use however, it also makes sense to talk about 'socioecological systems' instead of socio-technical systems. Socio-ecological systems can be defined as "complex and integrated systems in which mixed components of economic, social and environmental capitals interact across spatial scales (but within a geographically-bounded space) over a defined period of time" [19].

\subsection{Integrated Assessment Modelling}

Integrated Assessment Models (IAMs) have been developed to describe the key processes in the interaction between human development and the natural environment on a global scale, taking into account some of the key feedback and feed-forward mechanisms. Their aim is to provide a dynamic and long-term perspective of global environmental change by creating scenarios. These scenarios are based on socioeconomic and policy storylines and capture both direct and indirect land-use change. They are therefore an appealing tool for assessing the impacts of land use change on 
biodiversity [20]. IAM methods and tools draw on functional relationships between activities, such as provision of food, water and energy, and the associated impact [21]. These impacts include climate change, air pollution, water quality, water scarcity, depletion of non-renewable resources (e.g. fossil fuels, phosphorus), overexploitation of renewable resources (e.g. fish stocks, forests), and effects on biodiversity. IAMs can be a useful starting point for more detailed regional assessment, but they do not capture all impacts - changes in certain habitats, for instance, may be better identified by empirical studies [20].

IAMs are particularly useful to:

- Assess the relative importance of different linkages within the society-biosphereclimate system;

- Analyse the strength of different interactions and feedbacks;

- Estimate the consequences of various policy measures.

Often, a back-casting analysis is used to address transition pathways: given the difference between agreed long-term sustainability targets and the expected outcomes in a scenario without specific policies to achieve these targets, which short- and medium-term actions are required to achieve the long-term targets?

As an example, Figure 2 shows the interactions in the IMAGE integrated assessment model. In this model, changes in agriculture and land use are affected by drivers such as population and economic growth, policies, technologic change, lifestyle change, and change in resources. Agriculture and land use interact with energy supply and demand, for instance via bio-energy. Changes in land use affect the Earth system, such as vegetation, nutrient cycles, the water cycle, and the climate via changes in land use emissions. 


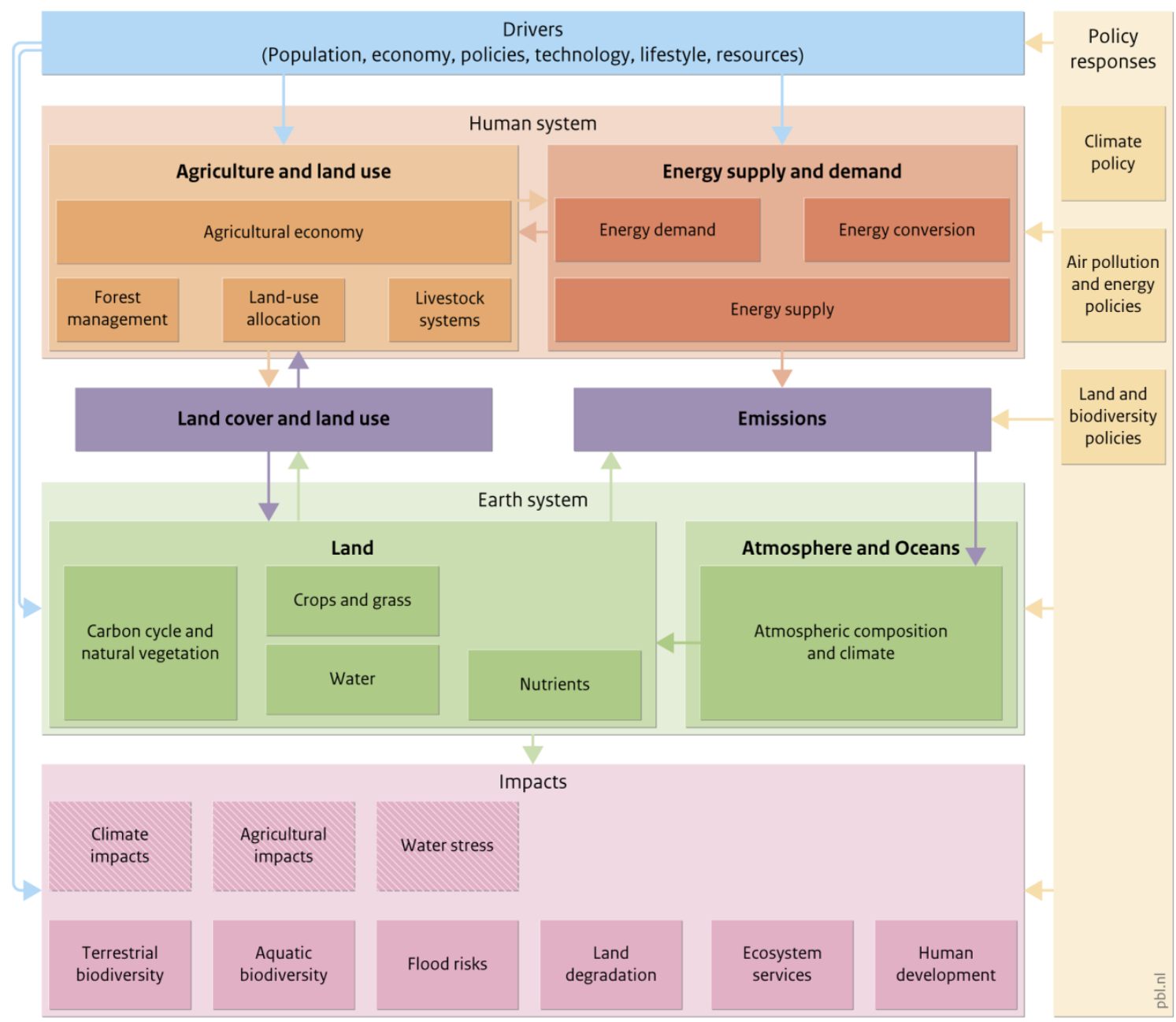

\section{Figure 2: IMAGE framework [21]}

An important limitation of IAMs is oversimplification of the transition process, due to only a limited attention to actors and their behaviour in these models. Furthermore, the scale of the model is important. A global model is not suited for regional or local analysis. However, global scenarios can quantify the impact on land use changes at a regional level, inform the debate on how actions affect opportunities and needs, and can help identifying potential conflicts between different goals [20] (for example enough food production, good farmers income and biodiversity goals). The focus of IAMs is very much on economic mechanisms, often ignoring important societal considerations. Furthermore, there is only limited attention to policy implementation. On the other hand, quite a number of explicit and implicit assumptions on factors like learning and investments are applied. The research and data behind these assumptions guide the interaction of cause and effect in the models. The realism of these assumptions is hence crucial to the validity of the models.

\subsection{Initiative-based learning}

IBL addresses the lowest aggregated level among the three approaches. It deals with the emergence, development and impact of real world activities that seek to instigate, replicate or cope with efforts that lead to regime transitions or emerge from them. It "focuses on real-life projects driven by a diverse set of actors that work as catalysts and nuclei for innovation towards transitions" [14, 22, p. 5]. 
In terms of socio-technical analysis, initiative-based learning may be related to "local projects". These form the sources of novel developments that may turn into innovative niches and even upscale to form new regimes. Initiative-based learning uses a diverse set of research methods to observe, explain or even support initiatives. For example, these activities can be analysed in traditional case studies with the researcher as an observer acting according to classic case study aims and methodology (as laid out by e.g. Eisenhardt [23] or Yin [24]). More pro-active approaches in the sense of actively intervening into a regime or instigating a transition come from approaches that can be subsumed under the heading of "transformative research". They seek to actively affect and promote a transition [25]. Such approaches may include experimental settings like participatory action research [26], LivingLabs [27] or real-world laboratories [28]. IBL also has a distinct aptness of producing concrete actionable knowledge for this level of analysis [30, 31].

IBL thus provides insights into the processes behind innovative projects. It is set where transitions begin, take-off or fail. These processes are generally not very transparent, as they are actor driven and affected by phenomena like ambitions, in-group interaction, network effects, needs for resource acquisition etc. [22] They are hence of a less ordered or even messy character [29].

Methods applied here need to take these specificities into consideration and are hence often of a hermeneutic and less abstract character. Strengths of this approach relate to its concreteness and orientation on problem solving or uptake. Of the three approaches included in this study, it is closest in respect to real life development and the direct processes involved in sustainability transitions. In return, it is less capable of deriving lessons regarding the "bigger picture" and its findings may be difficult to generalize, as they can be context-dependent [14]. Especially in the case of land use it is hard to foresee what will happen in the future, as developments in land use take some time before effects on, for example, biodiversity are visible.

\section{Findings from the research approaches}

Taken from the deliberations above, we suggest that a synopsis of the three approaches described can provide more intricate and useful insight into the role of innovations and the potential to reach multiple environmental goals as defined in IAMs. In this paper we focus on the case of agricultural nature conservation in the Netherlands and study this phenomenon on a local scale, from a multi-level perspective and from an IAM approach. The MLP approach studies the landscape, regime, and niches of Dutch agricultural nature conservation; IBL studies some practical struggles and successes of one nature conservation initiative in the Netherlands, called Water, Land and Dikes (WLD); and IAM looks at whether and how agriculture nature conservation could fit in a scenario in which different sustainability goals are achieved simultaneously, such as reaching the targets for GHG emissions and biodiversity and at the same time produce enough food for the growing world population.

\subsection{Findings from the MLP perspective}

Although agricultural nature conservation as such is not a recent phenomenon, from an $M L P$ perspective it can be regarded as an innovative niche as it is not business as usual 
nor an improvement of the current regime, but a type of land use in which agricultural production and nature conservation are combined. The question that can be asked from this approach is to what extent the niche is able to break through the existing agricultural and nature regime.

The dominant agricultural regime is characterised by agricultural intensification: a decreasing number of farms, and simultaneously an increase in the size of the farms in hectares or number of animals. Mechanization and the use of inputs such as water, marine resources, and minerals contributed to this trend. The agricultural regime is very locked in due to i) sunk investments, mainly by farmers; ii) hard-to-change culture and habits of farmers and consumers; and iii) the uneven distribution of power in the value chain leading to very few degrees of freedom on the side of the farmers. However, some cracks and tensions in this regime are visible which might lead to changes. These include more stringent regulations to counter environmental and public health problems, stronger societal awareness, and NGOs and the public opinion gaining more influence on the sector [32]. The license for farmers to produce is no longer taken for granted. Rising attention among consumers for healthy, authentic, sustainable, animal friendly, and locally produced products asks for different production methods [33, 34]. For some but not all - farmers, a solution to deal with decreasing incomes is to combine production with other activities in order to generate sufficient income, for example care, tourism or selling their own products.

The nature regime is less locked-in compared to the agricultural regime, as there are less incumbent and powerful players dominating the 'market'. The cracks and tensions in the nature regime are strong mainly due to decentralization of budgets from the (inter)national level to regional governments (provinces) [35]: policy on nature shifted from connecting nature areas organised on the (inter)national level to a partly decentralisation of responsibility to local and regional governments and deregulation of landscape policies [40], although the state remains responsible for the EU Natura 2000goals. This change of responsibility aims to realise measures which better correspond to characteristics of the specific region. At the same time, the link between economy and biodiversity is being put to the fore in order to find ways to improve both simultaneously (win-win solutions). The importance and positive impact of nature on society has also gained attention, with The Nature Alliance (Natuurpact, established in 2013) introducing the term 'natural capital'. The Nature Alliance is an arrangement between the national government and the provincial governments, in which agreements are made on developing the existing state targets for new nature (80 000 hectares), improving the biodiversity and reaching international Natura 2000 nature goals. Related to these developments, nature is increasingly combined with agriculture or water supply and financial resources from different sources are combined. This, together with budgets available for nature being under pressure [36], could spur niche-innovations on new ways to reward or finance agricultural nature conservation and more extensive agriculture.

Currently, the effectiveness of agricultural nature conservation is determined by 1) the degree to which measures lead to improvement of habitats of the target species; 2) the intensity of agriculture in the area in which measures are taken and 3) the structure and diversity of the area [37]. As the ecological effectivity of agriculture nature conservation has been limited so far, the system was changed in 2016 and budgets were 
decentralized: farmers can now only apply collectively for agriculture nature conservation in designated areas with large ecological opportunities. A first ex ante evaluation showed that in practice, not all of the designated areas have large ecological opportunities, which may limit the environmental impact of the new system [38, 39]. In fact, the regulations for nature agricultural subsidies in The Netherlands has been changed several times since 1975 - but with little success for nature conservation goals [41]. Farmers were participating on voluntary basis and could choose the kind of conservation measures they would like to apply. This resulted in many farmers choosing measures that were easy to implement but had low or zero ecological impacts [42]. Agricultural nature conservation may therefore not necessarily be the best solution to halt biodiversity reduction, but is an interesting niche to study for the future as it combines managerial and policy measures with technological measures in the field.

At the landscape level characteristics can be identified that have a stabilising effect on the land use domain and might both hinder or encourage the development of agricultural nature conservation. The landscape level of the agricultural sector is strongly determined by The Common Agricultural Policy (CAP) of the EU [43, 44]. The present CAP consists of two pillars: pillar 1 entailing a Common Market Organisation and pillar 2 with the Rural Development regulation of Agenda 2000. Pillar 1 lays out the rules for providing market price support measures as well as direct payments. Pillar 2 consists of a list of measures from which member states can choose. Funding in this pillar requires co-funding at national or regional level [45]. The CAP used to be a stabilizing factor, as it determines how the payments are organized. Adaptations of the CAP are discussed on the European level, and can hardly be influenced in the region. However, the CAP is currently changing as recently discussions have started on its design after 2020. This is an opportunity to organize change. Other possibly destabilizing factors are the increasing urgency to deal with climate change, the changing demand of consumers (such as increased global meat consumption and population growth), and crises (such as floods, animal diseases and the financial crisis).

Agricultural nature conservation was for a long time what we can call a stabilised niche: a part of nature conservation was arranged in combination with agricultural production, but it did not increase in momentum or changed the existing agricultural or nature regime. Recently, changes in the landscape and regime are occurring related to the discussions on changing the CAP and decreasing subsidies for nature conservation. Furthermore, discussions arise on the role of farmers in rural areas, as the farms and kind of agricultural activity determines to a large extent how the rural areas look like. For instance, there are discussions on license to produce for farmers. Helping maintaining the rural areas and taking measures to help nature conservation is one way to create a license to produce. In 2013, around 11\% (about 12 500) of all farms had contracts regarding nature or landscape management - which is a strong decrease from $27 \%$ in 2003 [15]. However, in terms of total area, agricultural nature conservation has been relatively stable since 2000 (Figure 3) [46]. The amount of subsidies that arable farmers get for nature and landscape is relatively small compared to the profit they receive from their farm, but stable (Figure 4) [47]. For $81 \%$ of the farms that have agricultural nature conservation as the only secondary activity, this activity provided less than $10 \%$ of their total income in 2010 (and in almost all previous years) [48]. It is expected that without subsidies, only a quarter of the farmers would keep on managing the nature and landscape on their farms, and that will only be the 'light measures' [49]. 
The main motivations for farmers to become involved in agricultural nature conservation are therefore increase of income [47], with idealistic reasons being a secondary motivation [50].

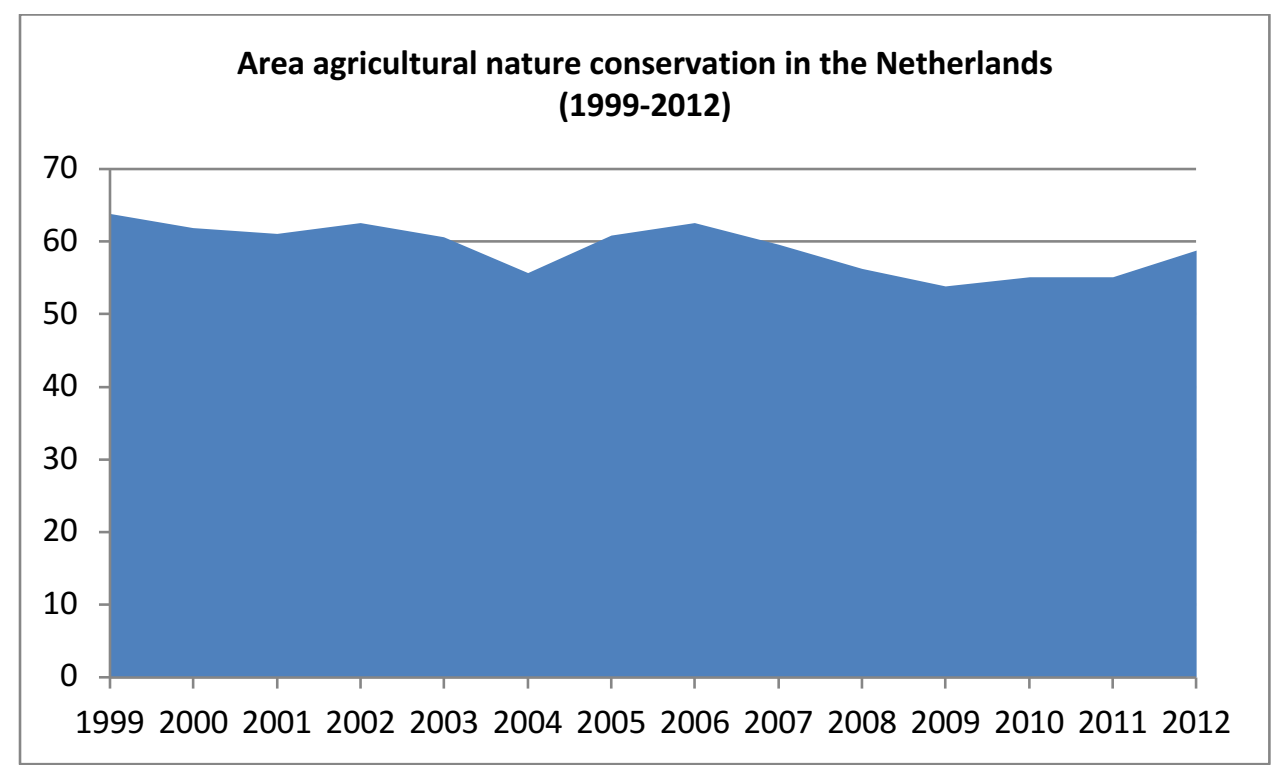

Figure 3 Total area agricultural nature conservation in the Netherlands (adapted from [46])

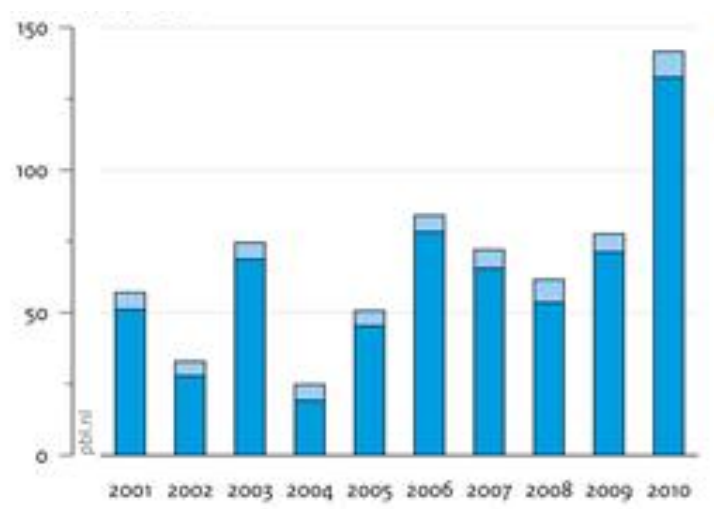

Figure 4 Income farmers (dark blue) and reward for nature conservation (light blue) in 1000 euros [47].

Besides farmers, around 75,000 volunteers (mainly citizens, often not living in the rural areas) were involved to help maintaining the existing nature and agricultural areas in 2015, by developing new areas suitable for agricultural nature conservation and developing recreation areas. These developments are not only influencing the farmers but also the people living in rural areas.

\subsection{Findings from the IBL perspective}

There are numerous Agricultural Nature Associations at local or regional level in The Netherlands, most of them established in the 1990s. These nature associations consist of people collaborating in the coordination and implementation of policies on agricultural nature conservation introduced by the government. The overall goal of an Agricultural Nature Association is improving the quality of nature and agriculture in 
their working area. The associations are mainly present in the northern and western part of the Netherlands as a lot of meadow birds live there. An example of such an Agricultural Nature Association Initiative is Water Land and Dikes (WLD), managed by farmers. The case is studied with the IBL perspective [51]: via interviews and document analysis the timeline of the case was reconstructed and insight was gathered on how the 'transition' process of WLD from an Agricultural Nature Association towards a collective responsible for developing new services occurred [51]. The focal question that was asked from this perspective is: What factors enable or disable the transition for initiatives on the ground that resemble 'transitions in the making'?

WLD has started as a result of the fusion of two organisations in 2007 that existed already since the early 1990s in the area Lower Holland, an area in the North-Western part of the Netherlands. WLD was able to make a quick start in its activities since they received substantial subsidies. This was mainly due to the 'natural handicaps' of the area, such as excessive water and many peat areas. Intensive agricultural production is hardly possible in this area, because not every piece of land can be reached by machines (or cows). This leads to lower income for farmers. There are, however, good conditions to combine nature and agriculture, and protect species that belong to the agricultural landscape in forms of multi-functional land use [52].

Multifunctional land use is per definition occurring at the borders of the agricultural and the nature regime, so the initiators have to deal with differences in regulations and actors between the different regimes and have difficulties in acquiring resources. Farmers would be less willing to participate in agricultural nature conservation if it would lead to less productivity, but since 1975 they are compensated for reductions in production resulting from nature conservation. Activities related to agricultural nature conservation are therefore dependent on subsidies and regulations.

Initially, the main goal of WLD was to protect meadow birds. Due to changes in the CAP and in national policy the goals of WLD became broader. One of the most important changes consists of a more prominent role for collectives: in the past, individual farmers could apply for payments for nature and landscape maintenance at the provincial level, whereas from 2016 onwards only collectives can apply for these payments. Farmers and agricultural land users sign contracts with these collectives [51]. Two other major recent changes in the CAP relevant for WLD were [53]:

- Greening: A share of the direct payments for farmers that nowadays compensate for the low world market prices will be based on green services.

- The range of services is broadened with other themes, such as water, soil and climate.

Based on this background and due to these changes, WLD developed into a project organisation with a lot of knowledge on agricultural nature conservation. They have established a great knowledge base and as a result, they are viewed by the (national) government as a serious partner. WLD proposed to start a pilot to practice with the role of collectives in CAP financed by the Ministry of Economic Affairs. After a selection procedure, WLD could develop their pilot from 2011 until 2014. In this course, WLD became regarded as a 'think tank' for the government. 
As mentioned above, one of the future tasks of WLD will be the distribution of subsidies to the farmers in the area. The motivation for organizing agricultural nature conservation in this way is to decrease administration and implementation costs for the government (from formerly $50 \%$ to $12-18 \%$ ) [54] as it is no longer the individual farmer but the collective that needs to apply for subsidies. Furthermore, it is expected that organizing agricultural nature conservation in local networks improves its quality because formerly a part of subsidies was given to parcels without nature values [51]. Figure 5 shows some of the most important events in the history of WLD.

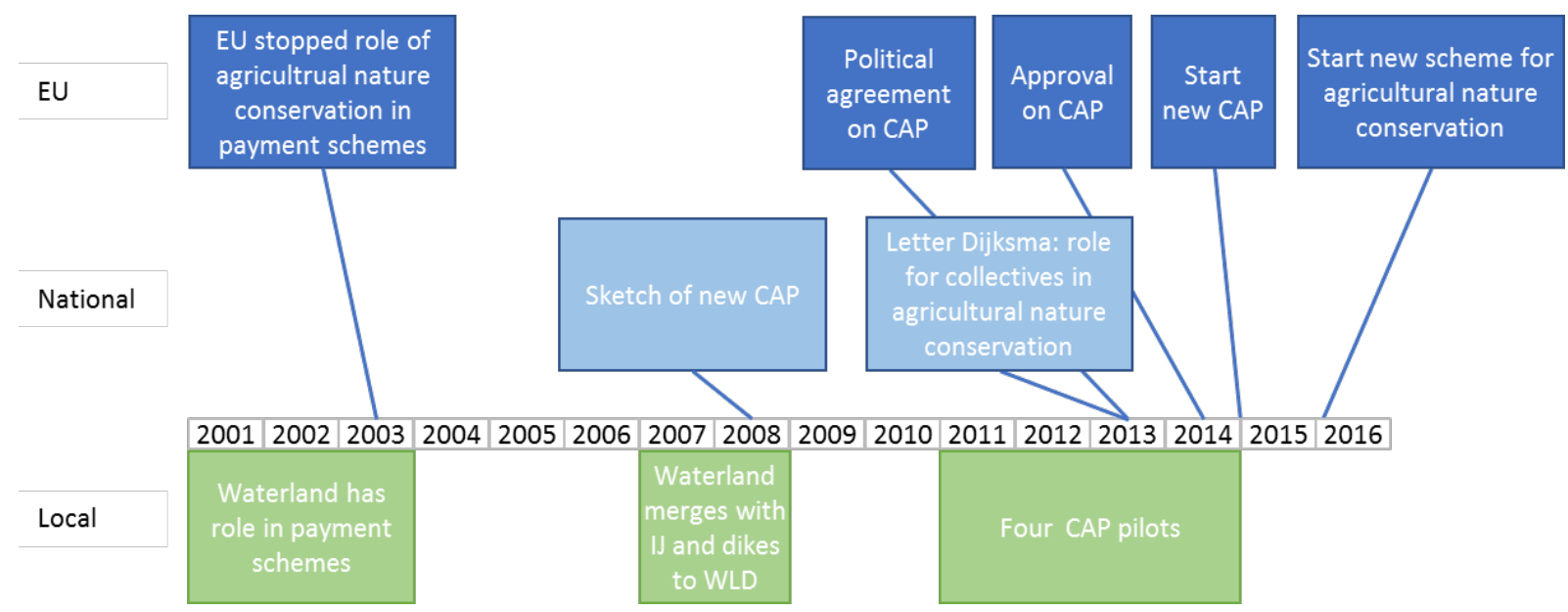

Figure 5: Timeline of most important events in the history of WLD.

The study of this local initiative revealed a strong governance influence. The government facilitated transitions by creating a space to innovate (by developing a pilot) and by providing subsidies, thereby creating a protected space for this innovation. However, ever-changing regulations led to uncertainties regarding the availability of subsidies in the future, making it difficult for farmers to take investment decisions. Hence, as long as high direct payments (based on production or area) exist, the incentive for agricultural nature conservation is limited. It will only be attractive for farmers to put effort in agricultural nature conservation if their production levels are insufficient. The focus will then be on production or landscape and biodiversity developments, while our study of interest is on the combination of the two. Therefore, it could be argued that subsidies could limit innovation as they only stimulate a development in the direction of higher yields. Furthermore, people will not be willing to invest in innovative ideas or new management tools if the future role of subsidies is unclear, as they run the risk of unprofitable investments.

The interviews in the case study showed that the local character of the organisation motivates people to join. An important reason for this is that farmers are approached by people from the organisation that know the area very well and know how to discuss measures or ideas. As such, locally organised initiatives can form a bridge between practice and policy. Some measures are more easily to take at a local level than at the national level, as the area specific characteristics as potential nature values of a parcel can be taken into account.

The developments around WLD illustrate the difficulties to encourage agricultural nature conservation with policy measures. As agricultural nature conservation needs to deal with two regimes (nature and agriculture), both with their own characteristics and 
institutions, it was sometimes hard to find measures that fit in both regimes. Different subsidy schemes existed for nature and agriculture. Combining them could simplify subsidy applications, but this is challenging as the goals and measures of the subsidy schemes sometimes conflict. For example, in order to improve biodiversity along the ditches, it is necessary to keep a certain amount of plants, while from the perspective of the water boards it will be better to mow all plants. Another difficulty is that due to the multifunctional character of the land, different payments have to be asked for at different institutions, demanding different information and implying a high level of bureaucracy.

Both the MLP and IBL analysis suggest that agricultural nature conservation strongly depends on subsidies, which implies that momentum may be vulnerable to changes in policy. The number of collectives is growing, as farmers can only receive subsidies via such collectives.

\subsection{Findings from the IAM perspective}

One of the major questions related to agricultural nature conservation addressed by IAMs is whether and how multifunctional land use, and especially agricultural nature conservation, could fit in a pathway that achieves biodiversity and other sustainability targets simultaneously. In an IAM approach Van Vuuren and Kok [55] and Van Vuuren et al. [56] have analysed alternative global pathways to achieve multiple sustainability goals by 2050. Long-term relationships between two clusters of sustainable development issues were analysed: food, land, and biodiversity on the one hand, and energy, air pollution, and climate change on the other hand. In one of these pathways (coined Global Technology), there was a strong technology-focus with intensive agriculture, potentially leading to land sparing [57, 58]. In another pathway (Decentralised Solutions), agriculture was assumed to be interwoven with natural corridors and national policies that regulate equitable access to food potentially leading to land sharing [59, 60]. In a follow-up study, Kok and Alkemade [61] specifically addressed the contribution of the agricultural sector to the realisation of biodiversity targets for the same pathways.

The Global Technology pathway reflects dynamics that lead to separation of agriculture and nature and can result in land sparing, reducing pressures on existing nature, and making space for rewilding. The Decentralised Solutions pathway reflects land sharing dynamics leading to better use of ecosystem services and more natural agriculture, but also a larger land requirement. The Decentralised Solutions pathway has strong similarities with our case study in which agricultural production and nature conservation are combined. Such landscapes can improve local ecosystems and connectivity between natural areas, but production improvements are easier to achieve in mono-functional agriculture by using cutting edge technological refinements, agronomic optimisation of the farm environment, and new animal breeds and crop varieties that perform best under these optimised conditions. However, this may lead to more local biodiversity loss compared to multifunctional land use. In multifunctional landscapes, higher yields may be achieved by combining the services provided by natural processes with technological advanced measures. 
The overall conclusion from the study is that there is a range of options required to halt global biodiversity loss. A substantial increase in agricultural productivity is required in both scenarios, but, as explained above, it will be lower in the Decentralised Solutions pathway than in the Global Technology pathway (Figure 6). Therefore, the Decentralised Solutions pathway requires more space for agriculture. To compensate for this, additional measures are needed to achieve biodiversity goals, such as cutting on infrastructural expansion and expanding natural areas. The study also shows that monofunctional and multifunctional agriculture both have significant scope for increased and more sustainable production, but both require improved land-use planning and will result in different types of biodiversity.

The analyses by Kok and Alkemade showed that substantial efforts will be needed to fulfil the conditions on which these pathways are based. For the Global Technology pathway, one of these conditions is that in the developed regions of the world, the annual yield increase needs to be the same as the average over the past 20 years $(1.3 \%)$. It will be challenging to achieve this, as agricultural productivity is already high in developed regions. This challenge can be illustrated by comparing the required yield increase in developed countries to the FAO projection of an annual $0.7 \%$ increase for the 2006-2050 period for the world as a whole [62]. In the Decentralised Solutions pathway, productivity increase will come from ecological solutions. In the currently intensivelymanaged landscapes of the United States and Europe, remnants of biodiversity are relatively scarce, putting ecological solutions at risk. This pathway therefore requires a profound change in these intensive farming systems, so that time and investments will be needed to improve degraded ecosystem services.

The IAM analysis shows not only the impact of multifunctional land use on greenhouse gas emissions and biodiversity loss, but can also help to show which type of practices are in line with long-term climate and biodiversity targets and food security and which scenario offers the most potential in which region. IAM shows that agricultural nature conservation can fit into different scenarios in which both biodiversity and climate targets are achieved, without endangering food security. However, as multifunctional land use is likely to lead to lower productivity improvements, additional measures are needed to both maintain farmer's income and to achieve biodiversity targets. In uncultivated areas, these additional measures could consist of limiting infrastructural expansion and expanding protected areas. This pathway asks for different changes simultaneously to reach the targets. 


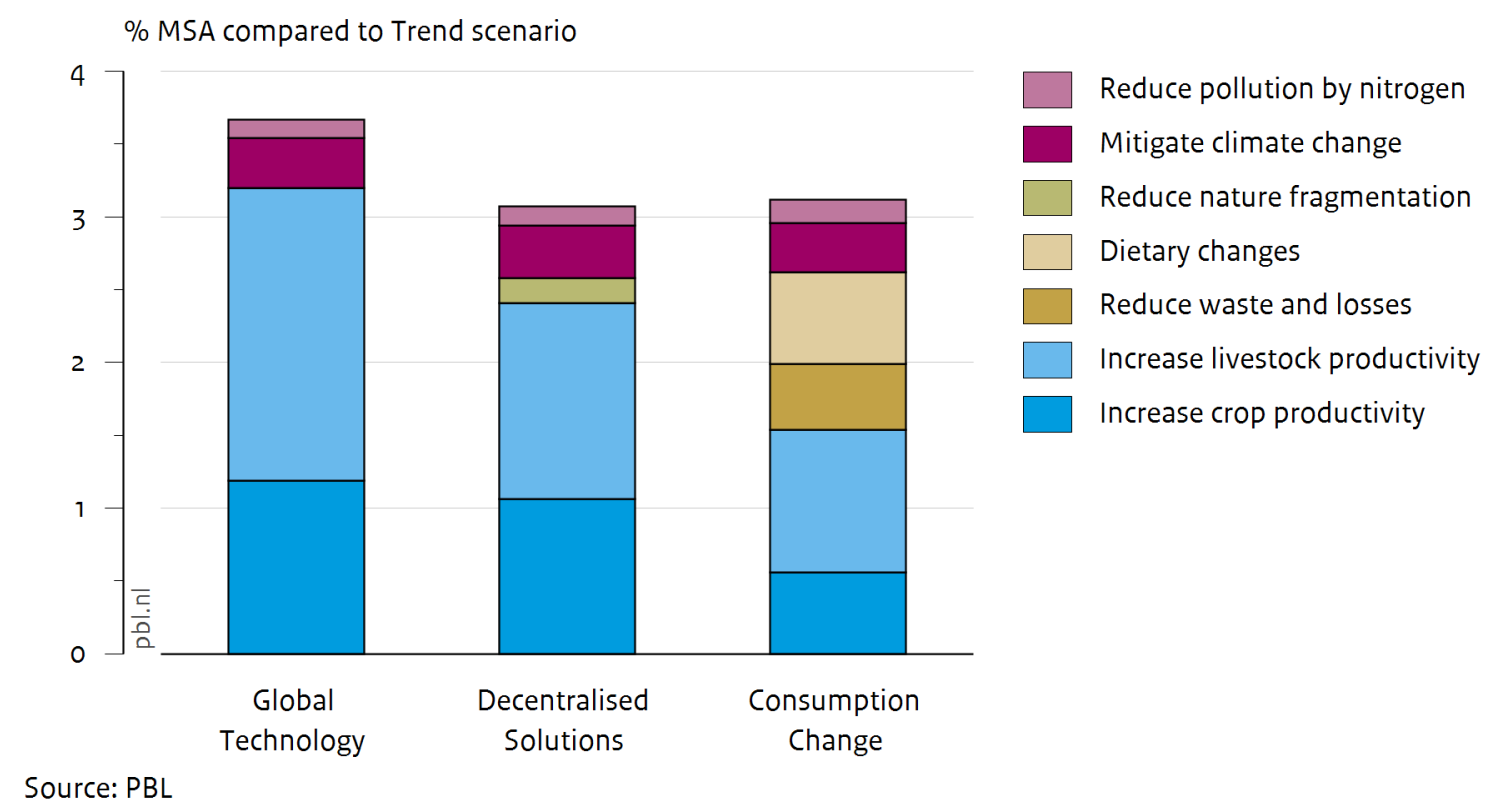

Figure 6: Options for reducing biodiversity loss by the food production sector [61]

\section{Combining the findings}

In this paper, we argue that a combination of scientific approaches to sustainability transitions can improve our understanding of such transitions. IAM defines potential measures to achieve global sustainability goals on biodiversity and climate while ensuring food supply, and MLP and IBL provide insights into what extent these measures are realistic based on current developments in the agricultural and nature regime and on practices at the local level (Figure 7). More specifically, MLP analysis delves deeper in how agricultural nature conservation, as a particular form of multifunctional land use, has been developing over time and can shed light on how changes can and should occur and what barriers and opportunities influence developments in that direction. IBL provides insights into how agricultural nature conservation is organised in practice. It shows the pitfall and obstacles met in practice and thus reveals implications for future measures. IAM analysis, finally, provides insights in whether and how multifunctional land use, and especially agricultural nature conservation, could fit in a pathway that achieves biodiversity and other sustainability targets simultaneously.

The MLP analysis showed that the niche agricultural nature conservation as a niche is already under development since the 1970s. Nowadays it seems that agricultural nature conservation is becoming part of the existing regimes, but its potential for growth is limited therein, as not all agricultural land will be used for agricultural nature conservation given its low potential value. Agricultural nature conservation can be seen as a stabilised niche: a movement that will not change the entire agricultural regime, but will remain small within this regime. In the framework of Geels and Schot [63] this transition can be defined as reconfiguration. The main actors are still the regime actors, but their role in the system is altered. Parts of the current practices are changing and new roles are developed: The role of the national government, for instance, is becoming less prominent. The main push for this niche to become mainstream seems to arise from the developments around the CAP and the decreasing subsidies in the nature regime that create cracks in the current agricultural and nature regimes, from which 
agricultural nature conservation could benefit. The limited impact of agricultural nature conservation on the ecological quality is an important reason why the momentum still remains small, although there might be types of combinations of nature and agriculture for which both the license to produce for farmers and the increasing urgency to halt the loss of biodiversity are taken into account. However, the IBL case on WLD shows it is not easy to combine measures for both the agricultural and nature regime. Furthermore, the case shows the power of a good relation with other organisations and of a wide knowledge base in making a quick start that could lead to successful niche innovation.

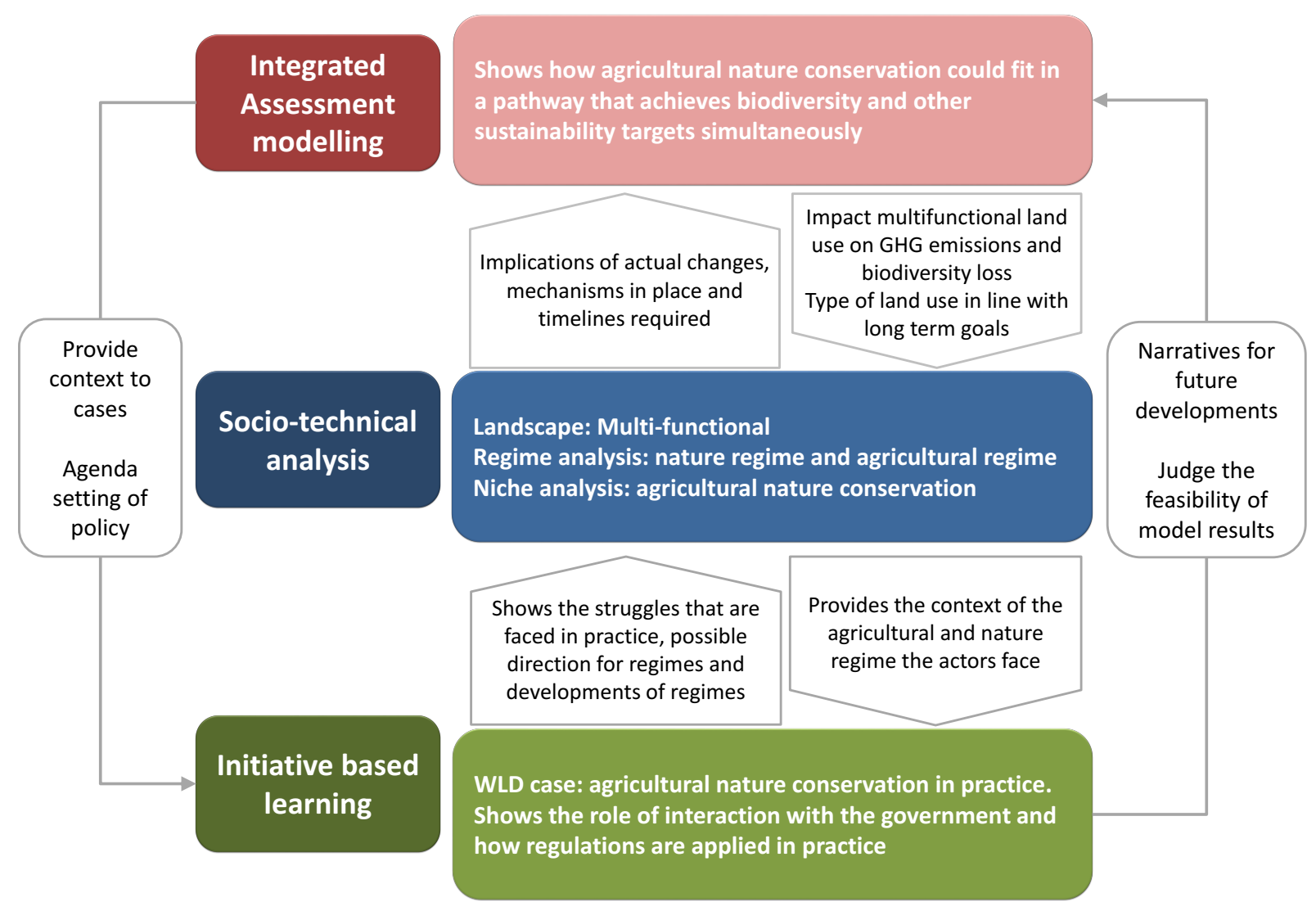

Figure 7: Integration between IAM, MLP, and IBL - an example of multifunctional land use in the Netherlands

\subsection{The relation between IAM and MLP}

IAM analysis shows that a regime shift towards multi-functional and mosaic landscapes could be consistent with long-term global and European sustainability targets regarding climate, food security, and biodiversity. It frames the findings of the Dutch regime into a formalized context offering foci and levers for future analysis and it provides the relevance of analysing multifunctional land use by showing that it could fit in a broader transition in which multiple sustainability targets are achieved. The MLP analysis suggests that developments in the agriculture and nature conservation regimes fit mostly in a global technology/intensification pathway. Therefore, one reason why developments in agricultural nature conservation are not easy to implement could be that they go against the dominant land use regime in the Netherlands. 
The MLP analysis shows how agricultural nature conservation is a niche developed at the borders of both the agricultural and nature regime. As both regimes have their own institutions and regulations, it is hard to realize innovations that have an impact in both regimes. MLP analysis shows how difficult it is to create such a development as characteristics of both regimes need to be taken into account. Furthermore, the effects on the ecology of agricultural nature conservation are only marginal, while there is a lot of financial support involved in agricultural nature conservation. Only when there is a fair and more fact based choice between the financing of broad and shallow or deep and thorough nature agriculture both the halt of biodiversity loss and the economic needs can be addressed at the same time.

\subsection{The relation between MLP and IBL}

By combining the MLP and IBL approach, we see how changes in the regime (especially the rules and regulations) influence the local initiative and the niche. The pilot of WLD is the result of changes in the landscape (namely the changes in the CAP), but is influencing the regime as well, as it sheds a light on how to deal with agricultural nature conservation in practice, e.g. by highlighting the difficulties in addressing the two regimes at once. As a prefiguration for a future shape of the regime this could indicate that a strong connection between the regime and niche or local initiative can help to make room for an innovation. If the regime actors are aware of their relations with the niche and local actors and the other way around, feedback between local initiatives and regime developments could be arranged to mutually improve the regime and the niche. Moreover, the distinct case in IBL showed how different regimes can affect each other directly through cross-regime of knock-on effects - a finding that would likely have gone unnoticed in single regime analysis.

\subsection{The relation between IAM and IBL}

In the current case, IAM results can help to show how measures can or cannot contribute to achieving multiple sustainability targets on a larger scale, which may increase the policy attention given to the implementation of agricultural nature conservation. It is important to note that agricultural nature conservation is one way of multifunctional land use, and probably even more important, multifunctional land use might not be the best solution to deal with halting biodiversity loss. However, IBL can be used to critically evaluate the storyline, underlying assumptions, and model parameters used in IAM regarding the transition towards multifunctional land use by validating these based on the analysis of real life cases. Insights from both MLP and IBL can help to strengthen the assumptions made in models.

While based on the IAM analysis one could argue that a multifunctional land use solution can be feasible, the MLP and IBL analyses reveal the struggles in practice when trying to deal with both regimes, and show that a multifunctional solution is often hard to realize. The IBL case is zooming in on one niche. It is too early to see the effect on the ecology of the measures taken in that very case.

\section{Conclusions}

Although the three perspectives used in this study have different time spans and focus on different developments, there are linkages visible. 
The IBL analysis mainly addresses the stubborn reality of the social practices and the interactive patterns of stakeholders. IBL cases can be an addition to MLP analyses as they can provide hints for future developments within a regime or for new configurations within or after a transition. Practices, products and institutions developed and observed within the initiative may e.g. work as role models. IBL can provide IAM with narratives for future development as pre-figurations: What will happen if a specific innovation scales up? In this case the initiative would be used to calibrate the parameters of a model, for example by showing how policy measures or new practices work out in practice. Moreover, observations from initiatives may be used to show the struggles related to implementation of measures taken in IAM scenarios. In this way, IBL can also help to judge the feasibility of future IAM projections or as experiments whose outcomes can be fit into the models for testing their scope. However, local practices can differ a lot between each other, which complicates connecting IBL with IAM outcomes.

MLP captures reality in a framework with multiple levels and multiple actors and systems. MLP could therefore draw implications on actual chances for change, timelines required and mechanisms in place (e.g. non-linear feedback in a locked-in environment). MLP can therefore validate the assumptions of IAMs, and sets the cases in IBL into a more encompassing timeline so that their role and significance in relation to past and present occurrences e.g. with regard to regimes and transitions becomes clearer.

IAM can provide supporting narrative storylines, context, and set goals to MLP, i.e. set an on-going or past transition into reference of broader approaches, future trends or projected development. Similarly, IAM can, just like MLP but in a different way, provide context and focus to IBL cases and initiatives. IAM can also be used to assess whether innovative ideas may be seen as parts of a solution, or whether they could be detrimental for certain sustainability targets on a larger scale. Moreover, IAM forecasts, e.g. on climate change, may work as motivators or set agendas to start initiatives or keep them going, as such projections tend to receive ample attention from policy makers and civil actors.

Our analysis thus provided first insights into how the combination of different research approaches may improve the understanding of certain empirical observations related to sustainability transitions - in our case the Dutch land use domain, or, more specifically, agricultural nature conservation. An assessment of the ecological quality of this measure is not part of such an analysis; instead, the focus is on governance measures. It is hard to generalise findings from one case study to a modelling exercise, but MLP and IBL can help to criticize the assumptions and storylines made in models. In the end, a lot of measures and changes ask for changes at the local level, and as our analyses show, studying real life interactions and social relations provide insight into these mechanisms. Analyzing transitions from a single approach already yield important insights, but a combined perspective caters for a deeper understanding of the underlying processes, reasons and motives and points towards potential future development and opportunities for intervention. Further research can built on these insights and concentrate on specific analytical foci, such as governance or developmental dynamics. Such approaches could meaningfully deepen the more exploratory analysis performed here and thus allow for further insights both into the 
topic of sustainability transitions and into possibilities of integration of different research approaches.

\section{Literature}

[1] E. Shove, G. Walker, Governing Transitions in the Sustainability of Everyday Life, Research Policy, 39 (2010) 471-476.

[2] M. Fischer-Kowalski, J. Rotmans, Conceptualizing, Observing, and Influencing Social-Ecological Transitions, Ecology and Society, 14 (2009) 3.

[3] P. Söderholm, R. Hildingsson, B. Johansson, J. Khan, F. Wilhelmsson, Governing the Transition to Low-Carbon Futures: A Critical Survey of Energy Scenarios for 2050, Futures, 43 (2011) 1105-1116.

[4] H.M. Pereira, L.M. Navarro, I.S. Martins, Global Biodiversity Change: The Bad, the Good, and the Unknown, Annual Review of Environment and Resources, 37 (2012) 25-50.

[5] IPCC, Summary for Policymakers, in: O. Edenhofer, R. Pichs-Madruga, Y. Sokona, E. Farahani, S. Kadner, K. Seyboth, A. Adler, I. Baum, S. Brunner, P. Eickemeier, B. Kriemann, J. Savolainen, S. Schlömer, C.v. Stechow, T. Zwickel, J.C. Minx (Eds.) Climate Change 2014, Mitigation of Climate Change. Contribution of Working Group III to the Fifth Assessment Report of the Intergovernmental Panel on Climate Change, Cambridge University Press, Cambridge, United Kingdom and New York, NY, USA, 2014.

[6] UNFCCC, FCCC/CP/2015/L.9/Rev.1: Adoption of the Paris Agreement, UNFCCC, Paris, France, 2015.

[7] H. Berg, Transitions of Energy Regimes - An Evolutionary Economic Interpretation, Josef Eul Verlag, Lohmar - Köln, 2013.

[8] S.M. Manson, Simplifying Complexity: A Review of Complexity Theory, Geoforum, 32 (2001) 405414.

[9] E. Mittleton-Kelly, Ten Principles of Complexity and Enabling Infrastructures, in: E. Mittleton-Kelly (Ed.) Complex Systems and Evolutionary Perspectives on Organizations - The Application of Complexity Theory to Organisations, Pergamon, Amsterdam, 2003, pp. 25-50.

[10] M. Gibbons, Mode 2 society and the emergence of context-sensitive science, Science and Public Policy, 27 (2000) 159-163.

[11] U. Schneidewind, M. Singer-Brodowski, Transformative Wissenschaft - Klimawandel im deutschen Wissenschafts- und Hochschulsystem, Metropolis, Marburg, 2014.

[12] D.T. Campbell, "Degrees of Freedom" and the Case Study, Comparative Political Studies, 8 (1975) 178-193.

[13] A. Dewulf, M. Craps, R. Bouwen, T. Taillieu, C. Pahl-Wostl, Integrated management of natural resources: Dealing with ambiguous issues, multiple actors and diverging frames, Water Science and Technology, 52 (2005) 115-124.

[14] B. Turnheim, F. Berkhout, F. Geels, A. Hof, A. McMeekin, B. Nykvist, D. van Vuuren, Evaluating sustainability transitions pathways: Bridging analytical approaches to address governance challenges, Glob Environ Change, 35 (2015) 239-253.

[15] Agriholland, Agrarisch natuurbeheer, http://www.groeneruimte.nl/dossiers/agrarisch natuurbeheer/, 2015.

[16] F.W. Geels, A. McMeekin, J. Mylan, D. Southerton, A critical appraisal of Sustainable Consumption and Production research: The reformist, revolutionary and reconfiguration positions, Global Environmental Change, 34 (2015) 1-12.

[17] F.W. Geels, Technological transitions as evolutionary reconfiguration processes: A multi-level perspective and a case-study, Research Policy, 31 (2002) 1257-1274.

[18] F.W. Geels, J.W. Schot, Typology of sociotechnical transition pathways, Research Policy, 36 (2007) 399-417. 
[19] A. Ferrara, C. Kelly, G.A. Wilson, A. Nolè, G. Mancino, S. Bajocco, L. Salvati, Shaping the role of 'fast' and 'slow' drivers of change in forest-shrubland socio-ecological systems, Journal of Environmental Management, 169 (2016) 155-166.

[20] L. Meller, D.P. van Vuuren, M. Cabeza, Quantifying biodiversity impacts of climate change and bioenergy: the role of integrated global scenarios, Reg Environ Change, 15 (2015) 961-971.

[21] E. Stehfest, D. van Vuuren, T. Kram, L. Bouwman, R. Alkemade, M. Bakkenes, H. Biemans, A. Bouwman, M. den Elzen, J. Janse, P. Lucas, J. van Minnen, M. Müller, A. Prins, Integrated Assessment of Global Environmental Change with IMAGE 3.0. Model description and policy applications, PBL Netherlands Environmental Assessment Agency, The Hague, 2014.

[22] H. Berg, L. Echternacht, B. J., Comprehension of case studies for MLP transition analysis in WP2, deliverable 3.3 of the PATHWAYS project, http://www.pathwaysproject.eu/sites/default/files/D3 3 ComprehensionCaseStudies May282015 web.pdf, 2015.

[23] K.M. Eisenhardt, Building Theories from Case Study Research, Academy of Management Review, 14 (1989) 532-550.

[24] R.K. Yin, Case Study Research- Designs and Methods, 5th edition, Sage, Los Angeles, 2014.

[25] WBGU, World in Transition. Social Contract for Sustainability. http://www.wbgu.de/en/flagshipreports/fr-2011-a-social-contract/ German Advisory Council on Global Change, Berlin, 2011.

[26] J.L. Ozanne, B. Saatcioglu, Participatory Action Research, Journal of Consumer Research, 35 (2008) 423-439.

[27] C. Liedtke, M. Hasselkuß, M.J. Welfens, J. Nordmann, C. Baedeker, Transformation towards sustainable consumption: changing consumption patterns through meaning in social practices, in: 4th International Conference on Sustainability Transitions: IST, ETH Zurich, Switzerland, 2013, pp. 702-729.

[28] F. Wagner, A. Grunwald, Reallabore als Forschungs- und Transformationsinstrument - Die Quadratur des hermeneutischen Zirkels, GAIA, 24/1 (2015) 26-31.

[29] C.J. Kirchhoff, M.C. Lemos, S. Dessai, Actionable knowledge for environmental decision making: Broadening the usability of climate science, Annual Review of Environment and Resources, 38 (2013) 393-414.

[30] C. Argyris, Actionable Knowledge: Design Causality in the Service of Consequential Theory, Journal of Applied Behavioral Science, 32 (1996) 390-406.

[31] N. Castree, W.M. Adams, J. Barry, D. Brockington, B. Büscher, E. Corbera, D. Demeritt, R. Duffr, U. Flet, K. Neve, P. Newell, L. Pellizoni, K. Rigby, P. Robbins, L. Robin, D.R. Rose, A. Ross, D. Schlosberg, S. Sörlin, P. West, M. Whitehead, B. Wynne, Changing the intellectual climate, Nature Clim Change, 4 (2014) 763-768.

[32] B. Elzen, F.W. Geels, C. Leeuwis, B. Van Mierlo, Normative contestation in transitions 'in the making': Animal welfare concerns and system innovation in pig husbandry, Research Policy, 40 (2011) 263-275.

[33] E. De Bakker, H. Dagevos, E. Van Mil, P. Van der Wielen, I. Terluin, A. Van den Ham, Vigourous searches for more sustainability in the agricultural and food sector: paradigms and practices Statutory Research Tasks Unit for Nature and Environment (WOt Natuur \& Milieu), Wageningen, 2013.

[34] LEI Wageningen UR, Monitor Duurzaam Voedsel 2013. Consumentenbestedingen aan duurzaam gelabelde producten, Ministerie van Economische Zaken, Den Haag, 2014.

[35] M. Schuerhoff, A. Ruijs, Geldstromen naar natuur - Ontwikkelingen van de financieringsstromen voor natuur- en landschapsbeheer tussen 1999 en 2013, PBL Netherlands Environmental Assessment Agency, The Hague. http://www.pbl.nl/sites/default/files/cms/publicaties/pbl-2016-geldstromennaar-natuur-erratum-met-erratum-2352.pdf, 2016.

[36] D. Kleijn, De effectiviteit van Agrarisch Natuurbeheer, Alterra, Centrum voor Ecosystemen, 2012.

[37] D. Kleijn, M. Rundlöf, J. Scheper, H.G. Smith, T. Tscharntke, Does conservation on farmland contribute to halting the biodiversity decline?, Trends in Ecology and Evolution, 26 (2011) 474 - 481.

[38] PBL, Balans van de Leefomgeving. Richting geven - Ruimte maken, PBL, The Hague, 2016. 
[39] T.C.P. Melman, A.M.v. Doorn, A.G.M. Schotman, F.F.v.d. Zee, H. Blanken, S. Martens, H. Sierdsema, R.A. Smidt, Nieuw stelsel agrarisch natuurbeheer: ex ante evaluatie provinciale natuurbeheerplannen, Alterra Wageningen UR, Wageningen, 2015.

[40] A. Buijs, T. Mattijssen, B. Arts, "The man, the administration and the counter-discourse": An analysis of the sudden turn in Dutch nature conservation policy, Land Use Policy, 38 (2014) 676-684.

[41] T.C.P. Melman, C.J. Grashof-Bokdam, H.P.J. Huiskes, W. Bijkerk, J.E. Plantinga, T. Jager, R. Haveman, A. Corporaal, Veldonderzoek effectiviteit natuurgericht beheer van graslanden: ecologische effectiviteit regelingen natuurbeheer: achtergrondrapport 2, Wettelijke Onderzoekstaken Natuur \& Milieu 56, Wageningen, 2007.

[42] H. Runhaar, Towards 'nature-inclusive' agriculture. Inaugural speech, Wageningen University \& Research, 2016.

[43] European Commission, The EU birds and habitats directives, Luxembourg, 2014.

[44] European Commission, Introduction to the new EU Water Framework Directive, http://ec.europa.eu/environment/water/water-framework/info/intro en.htm, 2015.

[45] OECD, Innovation, Agricultural Productivity and Sustainability in the Netherlands, OECD Publishing, Paris, 2015.

[46] CBS, PBL, W. UR, Realisatie nieuwe EHS-agrarisch natuurbeheer, 1999-2012 (indicator 1317, versie 10, 9 juli 2014), in: www.compendiumvoordeleefomgeving.nl, CBS, Den Haag; Planbureau voor de Leefomgeving, Den Haag/Bilthoven en Wageningen UR, Wageningen, 2014.

[47] R. Arnouts, G.J. Van den Born, F. Daalhuizen, H. Farjon, L. Pols, T. Tekelenburg, S. Tisma, M. Van Veen, A. Gerritsen, R. Verburg, M. Wiering, G. Roovers, Leren van het energieke platteland. Achtergrondrapport, PBL, Den Haag, 2013.

[48] A. Meurink, Natuurbeheer geen vetpot voor boeren, in, CBS, https://www.cbs.nl/nlnl/achtergrond/2010/26/natuurbeheer-geen-vetpot-voor-boeren, 2010.

[49] PBL, Leren van het energieke platteland. Lokale en regionale coalities voor duurzame plattelandsontwikkeling., in, PBL, Den Haag, The Netherlands, 2013.

[50] H. Leneman, C. Graveland, Deelnamebereidheid en continuïteit van het Agrarisch Natuurbeheer, LEI, Den Haag, 2004.

[51] J. Zwartkruis, H. Westhoek, Deliverable 3.3. Analysis of case studies. Sub-report: Case in the multifunctional land use domain in the Netherlands: Water, Land and Dikes, PBL, Bilthoven, 2015.

[52] P. Terwan, The Netherlands Case Study: Water. Land \& Dijken Association, OECD report Providing Agri-environmental Public Goods through Collective Action, (2013).

[53] Water Land \& Dijken, Lessen uit de GLB-pilot Laag Holland 2011-2014, in, 2014.

[54] P. Terwan, W. Rozendaal, Vergroenen van de landbouw doe je beter samen: Oefenen met een collectief leveringsstelsel voor vergroening en groenblauwe diensten - Lessen uit de vier GLB-pilots 2011-2014, pilots \%282014\%29-web.pdf, 2014.

[55] D.P. Vuuren van, M. Kok, Roads from Rio+20. Pathways to achieve global sustainability goals by 2050, PBL Netherlands Environmental Assessment Agency, The Hague, 2012.

[56] D. Vuuren van, Integrated assessment: Back to the Future. Inaugural Lecture, Utrecht University, Utrecht, 2015.

[57] D. Tilman, C. Balzer, J. Hill, B.L. Befort, Global food demand and the sustainable intensification of agriculture, Proc Natl Acad Sci U S A, 108 (2011) 20260-20264.

[58] B. Phalan, M. Onial, A. Balmford, R.E. Green, Reconciling Food Production and Biodiversity Conservation: Land Sharing and Land Sparing Compared, Science, 333 (2011) 1289-1291.

[59] M. van Noordwijk, L. Brussaard, Minimizing the ecological footprint of food: closing yield and efficiency gaps simultaneously?, Current Opinion in Environmental Sustainability, 8 (2014) 62-70.

[60] P. Tittonell, Ecological intensification of agriculture-sustainable by nature, Current Opinion in Environmental Sustainability, 8 (2014) 53-61.

[61] PBL, How sectors can contribute to sustainable use and conservation of biodiversity, CBD Technical series No 79, 2014. 
Paper prepared for special issue Technological Forecasting and Social Change

[62] N. Alexandratos, J. Bruinsma, World agriculture towards 2030/2050: the 2012 revision. ESA Working paper No. 12-03, FAO, Rome, 2012.

[63] F.W. Geels, J. Schot, Typology of sociotechnical transition pathways, Research Policy, 36 (2007) 399-417. 